14,13

\title{
Фотопроводимость вдоль границы раздела полимер/полимер
}

\author{
(C) А.Р. Юсупов ${ }^{1}$, А.Н. Лачинов ${ }^{1,2}$, Р.М. Гадиев ${ }^{1}$, Л.И. Рахматова ${ }^{1}$, Л.Р. Калимуллина ${ }^{1}$, Г.Ш. Байбулова ${ }^{1}$ \\ ${ }^{1}$ Башкирский государственный педагогический университет им. М. Акмуллы, \\ Уфра, Россия \\ ${ }^{2}$ Институт фризики молекул и кристаллов Уфимского фредерального исследовательского центра РАН, \\ Уфра, Россия \\ E-mail: Azat.yusupov@bk.ru
}

Поступила в Редакцию 24 сентября 2019 г.

В окончательной редакции 2 марта 2020 г.

Принята к публикации 10 марта 2020 г.

\begin{abstract}
Обнаружено влияние фотовозбуждения на электропроводность границы раздела двух полимерных пленок полидифениленфталида (ПДФ). Показано, что основной вклад на возникновение фотопроводимости оказывает ультрафиолетовое излучение. Установлена длительная релаксация фотопроводимости после прекращения освещения. На основе электрофизических измерений, а также сопоставления с результатами оптических исследований сделан вывод о влиянии ультрафиолетового излучения на величину дипольного момента.
\end{abstract}

Ключевые слова: диэлектрики, граница раздела, фотопроводимость, электропроводность.

DOI: $10.21883 /$ FTT.2020.07.49482.591

\section{1. Введение}

Граница раздела двух диэлектриков как органических [1], так и неорганических [2] обладает уникальными электронными свойствами такими как: высокая подвижность и большие концентрации носителей заряда; сверхпроводимость и гигантское магнетосопротивление [3]. Эти необычные свойства границы раздела двух диэлектриков связаны с возникновением вдоль нее двумерной структуры, содержащей квазидвумерный электронный газ (Q2DEG) [4]. Обнаружение свойств фотопроводимости в подобных структурах $\left(\mathrm{LaAlO}_{3} / \mathrm{SrTiO}_{3}\right.$, $\mathrm{LaGaO}_{3} / \mathrm{SrTiO}$ и $\mathrm{NdGaO}_{3} / \mathrm{SrTiO}_{3}$ [1]), позволило поновому оценить возможности практического применения таких материалов. Следует отметить, что особенности фотопроводимости данных структур схожи не только между собой, но и с другими двумерными структурами, например, на основе оксидов [5]. В том числе их объединяет большое время релаксации фотопроводимости после отключения освещения, что является следствием наличия Q2DEG [1].

В работе [6] было установлено, что вдоль границы раздела двух органических кристаллов тетратиофульвалена (TTF) и тетрацианахинодиметана (TCNQ) также возможно создать условия для формирования структуры, содержащей (Q2DEG) [4]. Аналогичные свойства были обнаружены вдоль границы раздела двух аморфных диэлектрических полимерных пленок [7]. В отличие от неорганических структур проводимость и подвижность носителей заряда в случае полимерной границы ниже. Тем не менее, они превышают объемные параметры по проводимости на 8 порядков, а по подвижности на 5-6 порядков [8]. Возможно более низкие значения этих показателей были обусловлены высоким уровнем дефектности границ раздела полимер/полимер, обуслов- ленным технологией получения этих границ (центрифугирование растворов и термический отжиг).

В работе [9] было показано влияние поверхностной поляризации боковых фрагментов полимерной молекулы в области границы раздела на электронные свойства границы. Изменение поверхностной поляризации вызывало изменение свойств границы. Можно предположить, что при фотовозбуждении полимера будут изменяться дипольные моменты фрагментов молекулы, что вызовет изменение электронных свойств границы раздела. Наблюдение таких изменений возможно при условии достаточно большого времени жизни возбужденного состояния. Исследования фотолюминесценции свидетельствуют о том, что релаксация короткоживущего синглетного состояния происходит через промежуточные долгоживущие триплетные [9].

В связи с этим, целью настоящей работы явилось исследование фотопроводимости вдоль границы раздела двух диэлектрических полимерных пленок.

\section{2. Объекты и методы исследования}

В качестве полимера был использован полидифениленфталид ранее применявшийся для формирования и исследования электронных свойств границ раздела полимер/полимер [7].

Исследуемые образцы представляли собой двуслойные полимерные пленки, между которыми были встроены медные электроды. Изготовление экспериментальных образцов проводилось в следующей последовательности: на предварительно очищенную стеклянную пластинку методом центрифугирования носилась полимерная пленка (из раствора полимера в циклогексаноне) толщиной $\sim 0.5 \mu \mathrm{m}$. После удаления остатков растворителя путем отжига при температуре $150^{\circ} \mathrm{C}$ в течение $40 \mathrm{~min}$, 
Size: $[19.92 \mu \mathrm{m} \times 19.92 \mu \mathrm{m} \times 145.9 \mathrm{~nm}]$
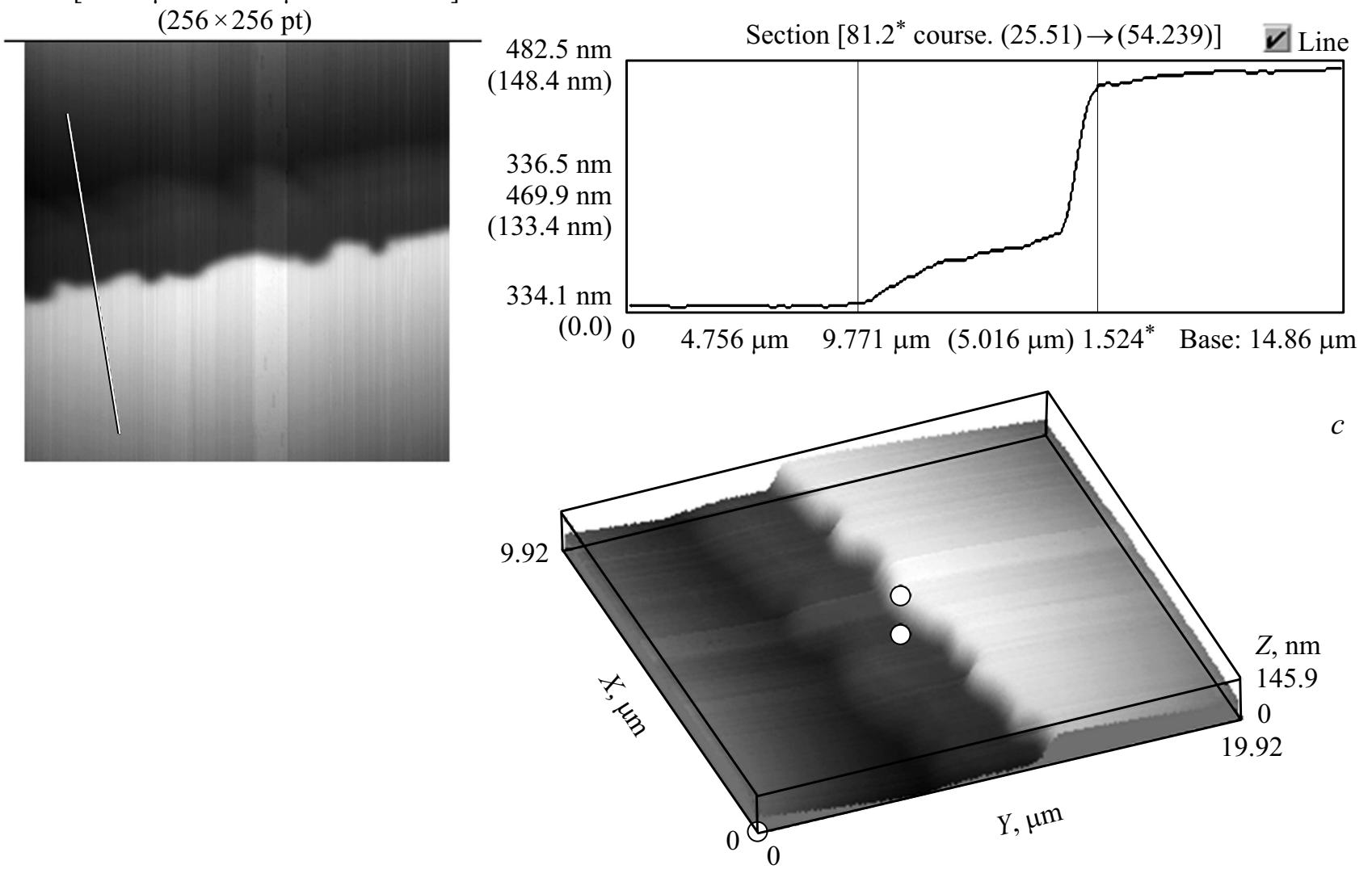

Рис. 1. АСМ-изображение края напыленной медной пленки, образованного теневой маской в виде проволоки толщиной $30 \mu \mathrm{m}$. На изображении видна линия, вдоль которой был построен профиль сечения. $a$ - двумерное изображение, размер скана $20 \mu \mathrm{m} \times 20 \mu \mathrm{m} \times 146 \mathrm{~nm}$. На изображении видна линия, вдоль которой был построен профиль сечения. $b-$ профиль сечения с измерительными линиями, позволяющий оценить линейные геометрические размеры и высоту наблюдаемых ступенек (конкретную толщину медной пленки). $c$ - трехмерное представление двумерного изображения.

наносились металлические электроды методом вакуумного термодиффузионного напыления, через теневую маску. В качестве материалов электродов использовалась медь. Последним этапом было нанесение второго (верхнего) слоя полимера методом центрифугирования с повторным отжигом образца при той же температуре. Расстояние между электродами задавалось с помощью проволоки диаметром $30 \mu \mathrm{m}$.

Цилиндрическая форма проволоки позволяла получать электроды в виде „лезвий“, направленных заостренными сторонами навстречу друг другу. Контроль качества нанесенных слоев полимера и металла проводили с использованием методов атомно-силовой микроскопии (АСМ). На рис. 1 представлены результаты исследования методом (АСM) края напыленного медного электрода. Толщина металлической пленки составила $150 \mathrm{~nm}$. Вблизи края зазора толщина уменьшается до $133 \mathrm{~nm}$. На профиле (рис. 1,b) виден переходный участок, в пределах которого толщина уменьшается до 30-35 nm и менее. Расстояние между встроенными электродами составляло $12 \pm 1 \mu \mathrm{m}$.

Важным аспектом границы раздела является толщина переходного слоя между полимерными пленками. Изуче- нию структуры такой границы раздела ранее было посвящено несколько работ $[7,8]$, в которых было установлено, что граница раздела представляет собой переходную область между полимерными пленками шириной от 5 до $12 \mathrm{~nm}$.

Контроль изменения электропроводности осуществлялся путем измерения и анализа вольтамперных характеристик (BAX). Измерения ВАХ проводились с помощью измерителя SourceMeter KEITHLEY 2400. Для контроля воспроизводимости результатов, измерения BAX проводили многократно. Освещение осуществляли по нормали к плоскости границы раздела. В качестве источников света использовались лазеры мощностью до $5 \mathrm{~mW}$ с длинами волн оптического излучения 405, 532 и $640 \mathrm{~nm}$.

\section{3. Результаты измерений и их обсуждение}

На рис. 2 показано влияние освещения на ВАХ, измеренные вдоль границы раздела полимер/полимер. Bce BAX имеют нелинейный вид, включая и темновую. 


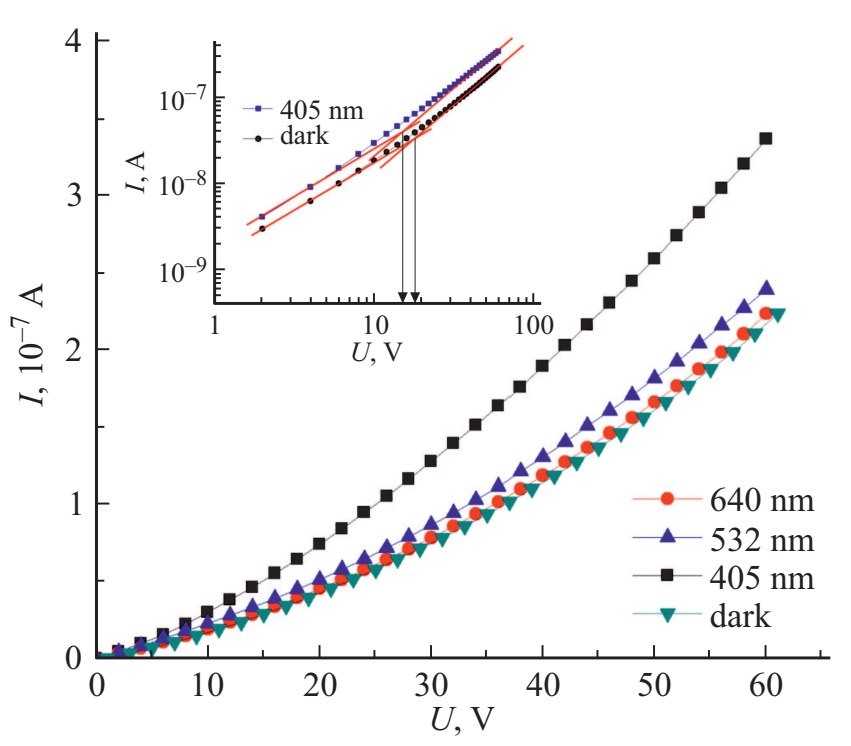

Рис. 2. ВАХ экспериментального образца при темновом измерении и фотовозбуждении. Во вложении ВАХ в двойных логарифмических координатах.

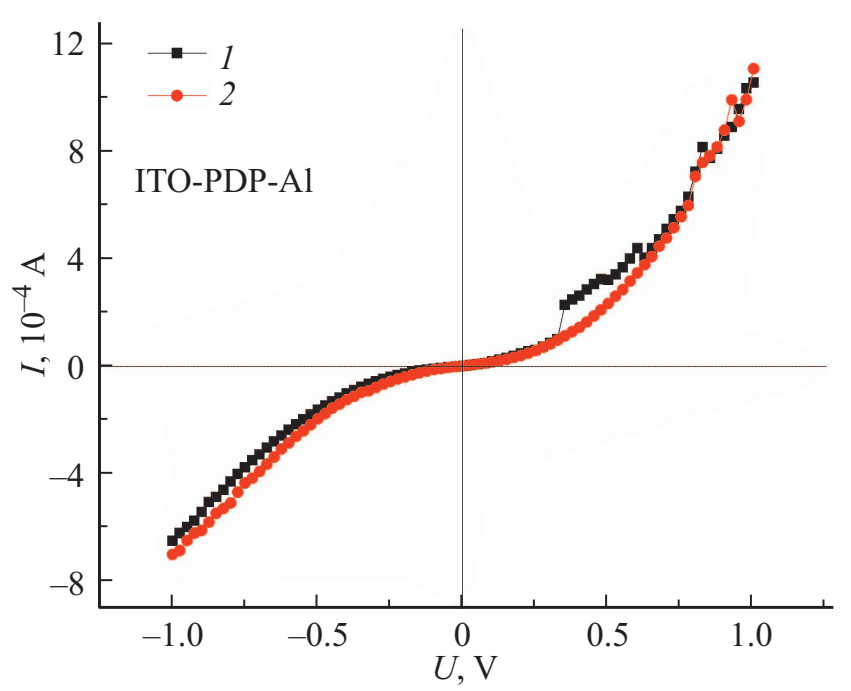

Рис. 3. ВАХ структуры ІТО-ПДФ-А1 полученные при темновых измерениях (кривая 1) и при ультрафиолетовом облучении (кривая 2). Толщина полимерной пленки в исследуемой структуре составляла $\sim 130 \mathrm{~nm}$.

Наименьшая проводимость регистрировалась при темновом режиме измерения. Освещение границы раздела приводило к увеличению проводимости. Наибольшее изменение регистрировалось при использовании источника с длиной волны $405 \mathrm{~nm}$. При $640 \mathrm{~nm}$ изменение проводимости практически не регистрируется, в то время, как при $405 \mathrm{~nm}$ возрастает при освещении в $\sim 1.5$ раза. Можно предположить, что обнаруженная фотопроводимость есть следствие объемной фотопроводимости пленок ПДФ. Проведенные контрольные измерения на монослойных пленках ПДФ в структуре металл/ПДФ/ITO (ITO - прозрачный полупроводниковый слой смеси окислов олова и индия) обнаружили наличие слабой фотопроводимости в пределах погрешности измерения только при обратном смещении. Относительное увеличение проводимости при $405 \mathrm{~nm}$ составило $\sim 5 \%$ относительно темновой (рис. 3). При других длинах волн изменений проводимости не было обнаружено. Дополнительные исследования фотопроводимости слоя ITO показали, что обнаруженное изменение сопоставимо с фотопроводимостью этого слоя, аналогичного, ранее описанному в работе [10].

Анализ нелинейных ВАX (рис. 3, вставка) в рамках модели токов, ограниченных пространственным зарядом [11] позволил оценить изменение подвижностей носителей заряда в результате облучения границы раздела полимер/полимер. Установлено, что подвижность возрастает с $7 \mathrm{~cm}^{2} / \mathrm{V} \cdot \mathrm{s}$ при темновом режиме измерения до $13.8 \mathrm{~cm}^{2} / \mathrm{V} \cdot \mathrm{s}$ при облучении светом длиной волны $405 \mathrm{~nm}$.

На рис. 4 представлена зависимость относительного изменения фототока $\left(I / I_{0}\right.$, где $I-$ фототок, $I_{0}-$ темновой ток) от напряжения, приложенного к экспериментальному образцу. На графике можно выделить две характерные области. В первой - наблюдается рост относительного изменения фототока, во второй уменьшение. Сравнение полученных результатов с видом BAX (рис. 2. вставка) показывает, что переход по напряжению от первой ко второй области совпадает с точкой перегиба на ВАХ. Это напряжение разделяет на BAX режимы транспорта носителей заряда. В области малых напряжений транспорт обусловлен собственными носителями заряда, при больших напряжениях носителями, инжектированными из электрода. Можно сделать предположение о том, что наибольшее влияние фотогенерация оказывает на концентрацию собственных носителей заряда (рис. 4, область I). Этот вывод очевиден,

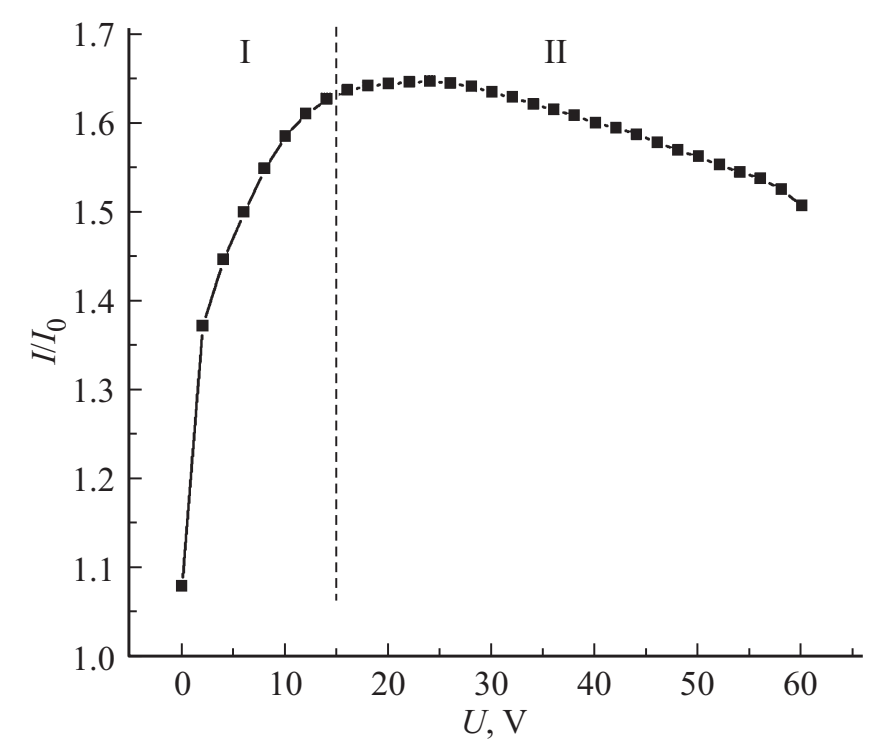

Рис. 4. Зависимость относительного изменения фототока от приложенного напряжения. 
так как освещение вблизи полосы поглощения влияет на характер заселенности вакантных электронных состояний выше уровня Ферми полимера. В области II доля „фотонечувствительных“ инжектированных из электрода носителей заряда, превышая концентрацию собственных носителей, компенсирует вклад фотогенерированных носителей заряда.

В процессе измерения ВАХ было установлено, что после начала засветки ток возрастает медленно и достигает своего максимума через 5-10s. При отключении источника света восстановление исходной низкой проводимости происходит в среднем в течении $35 \mathrm{~min}$. На рис. 5 представлена зависимость относительного изменения тока после отключения источника света. Полученную зависимость можно аппроксимировать экспоненциальной зависимостью с двумя четко выраженными участками с временами жизни $\sim 30 \mathrm{~s} \mathrm{и} \sim 50 \mathrm{~min}$.

Ранее, в работе [12], в пленках ПДФ было обнаружено длительное послесвечение флуоресценции. Кинетика послесвечения [12] объяснялась различной конформационной подвижностью разделенных зарядов, генерируемых при облучении полимера. Так начальное распределение активных центров таково, что часть из них либо расположена рядом (геминальные пары), либо локализована на концевых или боковых группах полимера со значительной молекулярной подвижностью. Первые „выгорают“ относительно быстро [12], и в полимере остаются разделенные заряды, экранированные друг от друга за счет сложной надмолекулярной структуры полимера. С учетом вклада таких активных центров, которые могут „жить““ достаточно долго, переход пленки из возбужденного состояния в основное может происходить достаточно долго. Интересно то, что спектры возбуждения короткоживущих состояний и долгоживущих различны. Долгоживущие состояния генерируются в полосе экситонного поглощения полимера с длиной волны максимума поглощения вблизи $405 \mathrm{~nm}$, в то время, как коротко живущие при $280 \mathrm{~nm}$ соответствующих полосе поглощения полимера.

Механизм формирования двумерной области вдоль границы раздела двух полимерных диэлектриков обусловлен наличием относительно большого дипольного момента бокового фрагмента ПДФ $\sim 5.6$ D. На повехности пленки боковые фрагменты создают дипольно упорядоченную структуру [13]. При фотовозбуждении электрон в результате непрямого перехода переходит с орбитали скелетной части молекулы на орбитали бокового фрагмента. Тем самым меняя его локальный дипольный момент. Ранее обнаруженный переход фотовозбужденного электрона в триплетное состояние стабилизирует это состояние на довольно продолжительное время, что мы и наблюдаем в эксперименте.

Изменение дипольного момента бокового фрагмента, как один из механизмов объясняющих наблюдаемую фотопроводимость в экспериментальной структуре на основе ПДФ находит подтверждение в результатах работы [14]. В ней использовалась реакция фотолиза

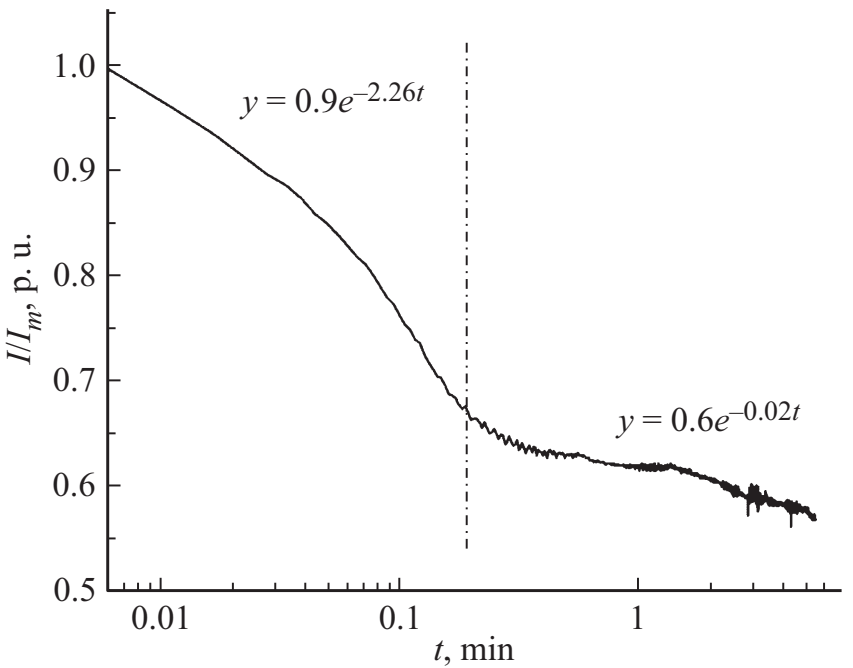

Рис. 5. Зависимость относительного изменения тока от времени $\left(I_{m}-\right.$ максимальное значение тока) после выключения освещения в двойных логарифмических координатах.

для модификации поверхности полиметилметакрилата (ПММА). Было установлено, что облучение ПММА используемого в качестве подзатворного диэлектрика в структуре полевого транзистора приводит к существенному улучшению характеристик транзистора за счет изменения дипольного момента боковой дипольной группы [15]. Этот механизм приводил к изменению заряженных состояний вблизи поверхности полимера. При этом длительность процесса релаксации фотопроводимости объяснялась возникновением отрицательно заряженных состояний, замедляющих процесс релаксации. В отличии от органических в неорганических материалов фотопроводимость с большим временем жизни $[5,16]$, объяснялась наличием сильных интерфейсных электрических полей [1], создаваемых фотогенерированными зарядами, разделенными вдоль границы раздела. Изначально фотопроводимость считали негативным эффектом усложняющим изучение свойств интерфейсов [17-19]. Дальнейшие исследования показали, что устойчивая фотопроводимость, вызванная излучением, является своеобразной особенностью полярных/неполярных интерфейсов [1]. В работе [1] фотопроводимость объяснялась тем, что при облучении происходило изменение электронной структуры слоя $\mathrm{SrTiO}_{3}$, приводящее к увеличению плотности поверхностных состояний. Последнее приводило к увеличению встроенного электрического поля. Ранее было показано [2], что для возникновения перехода типа изолятор-металл на поверхности $\mathrm{SrTiO}_{3}$ необходимо достижение поверхностного электронного состояния плотностью $10^{12} \mathrm{~cm}^{-2}$. Существующее в таких структурах пространственное разделение электронно-дырочных пар, создает значительное встроенное электрическое поле $[20,21]$ препятствующее процессу рекомбинации и приводит к очень длительным временам жизни фотовозбужденных состояний. 
Таким образом, в рамках настоящей работы, было установлено, что облучение границы раздела полимер/полимер в ультрафиолетовой области спектра приводит к росту электропроводности. Анализ работ на органических и неорганических структурах показал схожесть наблюдаемых эффектов, рассмотренных с разных позиций. В то же время наблюдаемая длительная релаксация фотопроводимости исследуемой структуры требует дальнейшего исследования.

\section{Финансирование работы}

Работа выполнена при поддержке гранта республики Башкортостан молодым ученым (договор 30ГР).

\section{Конфликт интересов}

Авторы заявляют, что у них нет конфликта интересов.

\section{Список литературы}

[1] Emiliano Di Gennaro, Umberto Scotti di Uccio. Carmela Aruta Adv. Opt. Mater. 1, 11, 834 (2013).

[2] H. Nakamura, H. Takagi, I.H. Inoue, Y. Takahashi, T. Hasegawa, Y. Tokura. Appl. Phys. Lett. B 89, 133504 (2006).

[3] M. BenShalom, M. Sachs, D. Rakhmilevitchetal. Phys. Rev. Lett. 104, 126802 (2010).

[4] A. Ohtomo, H.Y. Hwang. Nature London 427, 423 (2004).

[5] S. Ruhle, A.Y. Anderson, H.-N. Barad, B. Kupfer, Y. Bouhadana, E. Rosh-Hodesh, A. Zaban. J. Phys. Chem. Lett. 3, 3755 (2012).

[6] H. Alves, A.S. Molinari, H. Xie, A.F. Morpurgo. Nature Mater. 7, 574 (2008).

[7] Р.М. Гадиев, А.Н. Лачинов, В.М. Корнилов, Р.Б. Салихов, Р.Г. Рахмеев, А.Р. Юсупов. Письма в ЖЭТФ 90, 821 (2009).

[8] R.M. Gadiev, A.N. Lachinov, V.M. Kornilov. Appl. Phys. Lett. 98, 173305 (2011).

[9] Р.М. Гадиев, А.Н. Лачинов, Д.Д. Карамов, Д.А. Киселев, В.М. Корнилов. ЖЭТФ, 150, 1, 7 (2016).

[10] V. Brinzari, M. Ivanova, B.K. Cho, M. Kamei, G. Korotcenkov. Sensors Actuators B 148, 427 (2010).

[11] М.А. Ламперт, П. Марк. Инжекционные токи в твердых телах. Мир, М. (1973).

[12] В.А. Антипин, А.Н. Лачинов, Д.А. Мамыкин, А.А. Ковалёв, С.С. Остахов, В.В. Шапошникова, С.Н. Салазкин, В.П. Казаков. Химия высоких энергий 44, 4, 345 (2010).

[13] А.Н. Лачинов, В.А. Антипин, В.П. Казаков, А.А. Ковалев, С.Н. Салазкин, С.Б. Мешкова. Теор. эксп. химия 45, 1, 42 (2009)

[14] H.-W. Zanz, K.-H. Yen. Electrochem. Solid-State Lett. 11, 8, 222 (2008).

[15] A. Torikai, M. Ohno, K. Fueki, J. Appl. Polym. Sci. 41, 1023 (1990).

[16] E. Assmann, P. Blaha, R. Laskowski, K. Held, S. Okamoto, G. Sangiovanni. Phys. Rev. Lett. 110, 078701 (2013).

[17] S.P. Thiel. Study of Interface Properties in $\mathrm{LaAlO}_{3} / \mathrm{SrTiO}_{3}$ Heterostructures. PHD Dissertation, Augsburg (2009).
[18] M. Huijben. Interface Engineering for Oxide Electronics: Tuning electronic properties by atomically controlled growth. $\mathrm{Ph}$. D. thesis, University of Twente, Enschede, The Netherlands (2006).

[19] M. Huijben, G. Rijnders, D.H.A. Blank, S. Bals, S. VanAert, J. Verbeeck, G. Van Tendeloo, A. Brinkman, H. Hilgenkamp. Nature Mater. 5, 556 (2006).

[20] E. Kioupakis, Q. Yan, ChrisG. VandeWalle. Appl. Phys. Lett. 101, 231107 (2012).

[21] E. Arslan, S. Bütün, S. BoraLisesivdin, M. Kasap, S. Ozcelik, E. Ozbay, J. Appl. Phys. 103, 103701 (2008).

Редактор Т.Н. Василевская 